\title{
Research on the Enlightenment of French Engineers' Education on the Training Program of Internet of Things Engineering in China
}

\author{
Wu Jianfei ${ }^{1}$,, Xu Tiantian ${ }^{2}$, Wang Hongyi ${ }^{1}$, Zheng Liming ${ }^{1}$ \\ ${ }^{1}$ College of Electronic and Engineering, National University of Defense Technology, Changsha, China \\ ${ }^{2}$ Department of Internet of Things, Tianjin Binhai Civil-military Integrated Innovation Institute, Binhai, Tianjin, China
}

\section{Email address:}

wujianfei990243@126.com (Wu jianfei),1473551045@qq.com (Xu Tiantian),wanghongyi2011@163.com (Wang Hongyi), lmzheng@nudt.edu.cn (Zheng Liming)

${ }^{*}$ Corresponding author

\section{To cite this article:}

Wu Jianfei, Xu Tiantian, Wang Hongyi, Zheng Liming. Research on the Enlightenment of French Engineers' Education on the Training Program of Internet of Things Engineering in China. Science Innovation. Vol. 5, No. 2, 2017, pp. 77-82. doi: 10.11648/j.si.20170502.12

Received: January 18, 2017; Accepted: March 16, 2017; Published: March 29, 2017

\begin{abstract}
Nowadays, Internet of Things (IOT) are used more and more widely, and showed continued hot situation. IOT is a strategic emerging industry in China. To meet the modern industrial society, the development of global economic integration of the general direction, it is a Chinese future development trend in higher engineering education to establish high-quality, distinctive engineering colleges. In order to cultivate a group of international engineering education background, and innovative Chinese characteristics of IOT engineering personnel, the French engineers education modes are studied in this paper. And its status are compared with Chinese IOT education. This paper discusses the existing IOT teaching situation in China from three aspects: the team learning, cooperating with the French engineer school and the deep-level school-enterprise cooperation teaching methods. The paper contributes to the systematization and diversification of the talented personnel training plan of our excellent engineers.
\end{abstract}

Keywords: French Engineer Education, Internet of Things, Team Learning, Deep-Level School-Enterprise Cooperation

\section{关于法国工程师教育对中国物联网工程专业培养方案启示的研究}

吴建飞 ${ }^{1^{*}}$, 徐甜甜 ${ }^{2}$, 王宏义 ${ }^{1}$, 郑黎明 ${ }^{1}$

${ }^{1}$ 电子科学与工程学院, 国防科学技术大学, 长沙, 中国

${ }^{2}$ 物联网事业部, 天津市滨海新区军民融合创新研究院, 天津, 中国

\section{邮箱}

wujianfei990243@126. com（吴建飞）, 1473551045@qq. com（徐甜甜）, wanghongyi2011@163.com（王宏义）,

1mzheng@nudt. edu. cn（郑黎明）

摘要：物联网在当今的使用范围越来越广，并且表现出持续大热的形势。为了迎合现代工业社会全球经济一体化的发 展大方向, 办出高质量、有特色的工科院校, 是中国高等工程教育的未来发展趋势。为了培养出一批具有国际工程教 育背景、富有创新精神的中国特色物联网工程人才, 本文通过对法国工程师教育模式的研究, 将其与中国的物联网教 育现状进行对比。从小组研习的教学方式、与法国工程师学校合作的教学形式、深层次校企合作的教学方法这三个方 面对中国现有的物联网专业的教学现状进行了探讨与研究, 为我国的创新型物联网专业人才培养提供了新思路。 
关键词: 法国工程师教育, 物联网专业, 团队学习, 深层学校企业合作

\section{1. 引言}

物联网—— “物物相连的互联网”，被人称继计算机、 互联网之后, 将掀起世界信息产业的第三次信息时代大革 命。物联网仍然是互联网, 是在互联网基础上与现实的交 互，其用户端将任何物品与物品之间，进行信息交换和通 信。2009年 “智慧地球” 这一概念的首次提出, 开始了新 一代的智慧型基础设施的建立。同年 8 月, 由于 “感知 中国” 概念的出现，物联网被正式列为国家五大新兴战略 性产业之一，2010年教育部推行的 “卓越工程师教育培养 计划”，2011 年国家发布了物联网 “十二五” 的发展规 划, 将中国的 “物联网” 的研究与开发推入了高潮 [1]。

物联网的产业价值、经济价值及战略意义不可估量, 物联网正成为各国政府、大型企业急于占领的新兴市场, 美国将物联网列为2016-2045年新兴科技与经济增长重点。 根据麦肯锡的预测, 至2020年, 全球物联网市场将形成4 万亿元的规模, 中国政府站在国家战略高度积极扶持物联 网行业的成长, 在十二五规划、十三五规划中都对物联网 进行了重点阐述与战略布置、保持了支持物联网政策的连 续性，2016年中国物联网市场规模为9300亿，十二五期间 符合增长率约为 $25 \%$, 公众网络机器到机器连接数突破了 1 亿大关, 占全球总量的 $31 \%$, 已成为全球最大市场。所以 要进一步营造鼓励创的新环境, 努力造就世界一流科学家 和物联网领军人才。一流创新人才的涌现使全社会创新智 慧竞相发展、各方面创新人才大量涌现。在国家与国际相 互融合, 共同进步的同时, 国家物联网专业的应用人才也 要与国际接轨。《福斯特》曾有专题文章指出: 中国企业 需要创新思维的人才才有可能达到苹果公司的水平。可见, 高等工程教育在现代社会的经济发展中面临挑战, 需要创 新。目前, 全国已经开设了物联网专业的高校有不少, 但 对物联网专业的教学研究尚处于起步阶段, 培养出具有国 际工程教育背景、富有创新精神的中国特色物联网工程人 才，对中国的发展至关重要。

法国是公认的世界工业强国，其核能、航空、钢铁等 领域的发展举世瞩目, 在电子、电信、医疗等方面也拥有 不少的科技成果。从某种程度上说这些成就与法国的工程 师培养体系密切相关。工程师教育是法国精英教育的典型, 它为法国培养了大量精英和领军人才。由 “大学校” 实施 的工程师学历教育。法国的 “大学校” 体制在其他国家找 不到完全对等的形式, 是典型的法国特色, 是培养高级工 程技术人员和其他各类专业人才的高等教育机构。这是典 型的精英教育体制, 培养出密特朗、希拉克和诺斯潘等杰 出的国家领导人, 还有大公司的总裁、高级工程师等社会 高层人士, 使得法国的工程师学校及工程师学历教育在社 会上有很高的认可度。

通过对法国工程师教育模式的研究, 将其与中国的物 联网教育的国情相结合, 为中国的创新型物联网专业人才 培养提供新思路。

\section{2. 中国物联网工程专业培养方案现状}

自2010年3月教育部对各高校发出建立物联网专业学 科的号召起, 目前中国已经开设了物联网专业的高校有不 少, 但对物联网专业的教学研究尚处于起步阶段, 还没有 形成完整的教学理论与实施体系。

物联网通信技术是一门实践性很强的课程, 学生不仅 仅需要理解基础的理论知识, 还要有解决实际问题的能力。 但从现有的资料来看, 中国的高等教育普遍存在层次单一、 没有将理论与实践结合等问题, 课程学习多为老师课堂讲 解, 学生听, 这也导致了学生创新能力的不足。尽管有一 些实践课程, 但是受中国传统教育观念的束缚, 使得在实 践环节中也大多数是老师动手讲解, 学生按照老师的步骤 实践, 这样并不能起到培养学生创新能力的作用。而且虽 然大多数学校针对物联网工程专业已开设了无线传感器 网络、无线通信技术等专门课程, 但也保留了已有的计算 机网络等课程作为物联网工程专业通信技术的主干课程。 因为课程建设的不够完善, 使得物联网专业的核心知识在 课程中十分分散; 课程结构和学时分配也不够优化, 使得 学生理论知识涉及方面广泛但是涉及层次不足。

美国加州理工学院的一名教授曾说过这么一句话, “科学家研究已有的世界, 工程师创造未有的世界”。目 前, 我国的工程教育规模位居世界前列, 2012年高等教育 工程类本科在校生接近 400 万, 研究生接近 50 万。这基数 巨大, 但在结构和质量方面则不尽如人意。在我国现有的 技术从业者中，技师和高级技师的比例仅占 $1.5 \%$, 高级技 工占3. $5 \%$, 中级技工占 $35 \%$, 初级工占 $60 \%$ 以上; 而发达国 家的技术从业者中, 高级工占 $35 \%$, 中级工占 $50 \%$, 初级工 只占 $15 \%$ 。结构不合理是我国工程人才发展的瓶颈, 这制 约了我国的科技进步和经济发展。据《财富》杂志公布的 最新数据, 中国 “适应全球化要求” 的 “合格工程师” 有 16 万人, 占全国工程师总数的 $10 \%$ 不到。而印度合格工程 师的数量超过其总数的 $70 \%$ 。不难看出我国工程师的培养 质量与其他工业强国相比还存在很大的差距 [3]。在这样 的大背景下, 体现了我国在物联网人才培养方面的问题。

基数大、创新能力不强、人员结构不合理这就是中国 现阶段物联网工程人才的现状。

\section{3. 法国工程师教育的启示} 特点:

观摩法国的工程师教育, 会发现法国教育有以下几个

(1) 招生条件严格, 学生起点高。在进入工程学校 要经过高中毕业会考 $(\mathrm{BAC})$ 和工程师入学选拔考试两个选 拔严格的考核。

(2) 工程师学校的部分课程是与企业共同制定的, 并根据企业的需求不断调整教学内容。学生的研究题目也 大多来源于企业。在为期 3 年的学习中, 第一学年是基础 
理论教育, 第二学年主要开设专业理论课、实习课和实验 课。第三学年的主要任务是即为期半年的企业实习及撰写 论文并准备答辩。学校在培养学生专业技能的同时, 也重 视其综合能力的培养 [2]。

（3）企业实习是工程师教育中十分重要的环节，工 程师学校的学生在 3 年的学习过程中一般有两到三次的企 业实习。他们的校企合作涵盖从学生的教学, 毕业前的实 习, 到项目的科研合作, 层层深入。毕业生往往能够在还 没毕业前就能实习的方式在合作企业中进行第一次就业。

对此, 可以在以下三个方面对我国高校的物联网专业 进行改革。

\section{1. 改进教学形式}

对比法国高级工程师教育:

在理论教学上, 中国多以教师在课堂上以教材为依据 传授知识为主, 考核也多数以教材为准; 而法国工程师学 校除了进行课堂讲解和考试外, 老师还常常会根据理论课 的内容提出课题, 并以小组为单位, 自行研究完成各自的 课题, 以此作为考核凭证。
在实验教学上, 中国多以教师操作为主, 学生是跟随 老师操作为主, 这样没有达到实验教学的真正目的。而法 国工程师学校的实验课程, 教师则只负责简单的讲义讲解, 学生则要自行根据讲义, 协同合作进行实验, 问题无法解 决时再向教师请教。这样的做法使得学生需要自己结合理 论, 并且进行深入思考后, 才有可能正确完成实验, 完成 实验报告。

在物联网专业的教学中, 应该将理论教学和课程实践 穿插进行, 实践教学的进度应与理论教学一致。选择一个 完整的物联网项目，按照传感技术、接入技术、网络技术、 应用技术和安全技术等物联网核心技术进行分解，如图1; 将物联网的所有课本知识融入到项目中去, 以项目为依托, 将物联网工程的典型工作转化为专业课程, 如表 1 。老师 进行理论讲解, 同步进行实践课程。

实践课程中老师只提出项目课题, 让学生以小组为单 位进行理论知识梳理和课题研究, 完成报告。报告成绩计 入期末总成绩。这样的教学过程将学生放到中心地位, 教 师只参与引导、帮助、鼓励与最后点评。

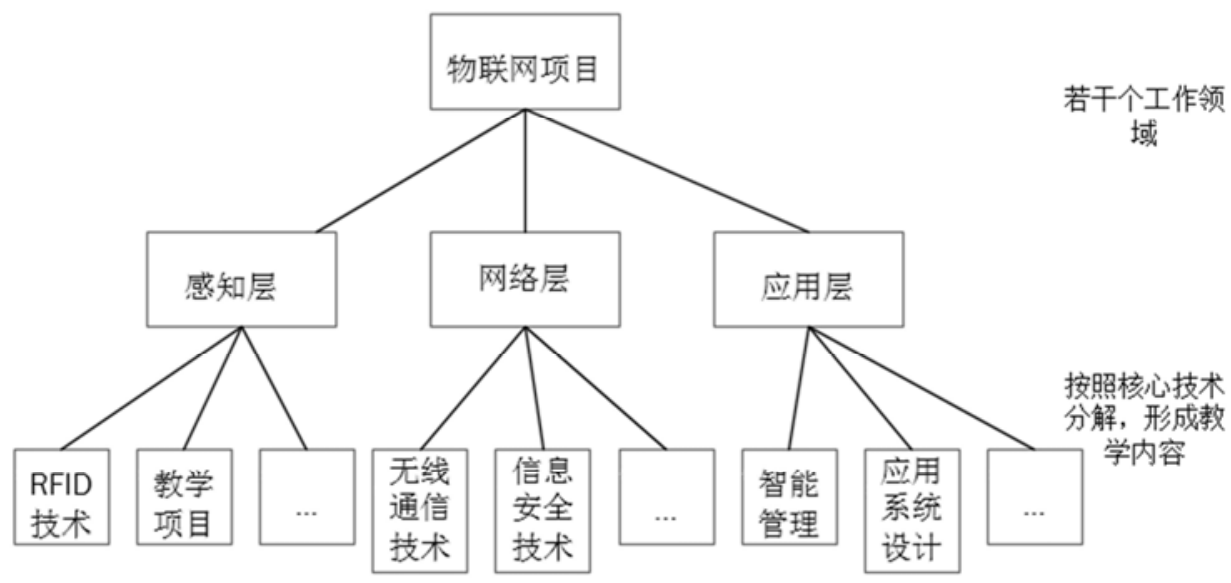

图1 课程体系建立。

表1 课程分析。

\begin{tabular}{lll}
\multicolumn{2}{l}{ 物联网项目的典型工作与专业课程对比 } \\
\hline 编号 & 典型工作名称 & 专业课程名称 \\
\hline 1 & 射频识别系统RFID设计与实现 & RFID系统设计与实现 \\
2 & 无线传感器网络构建与设计 & 无线协议设计 \\
3 & 无线传感器节点设计与开发 & 无线传感器节点设计与开发 \\
4 & 无线传感器网络信息远程获取 & 无线传感网络监控的实现 \\
5 & 设备疑难故障的判断与处理 & 物联网设备故障处理与维修 \\
\hline
\end{tabular}

这样子的教学形式不仅仅是传授事实性的知识, 更重 要的是让学生在尽可能真实的职业情境中学习 “如何工 作” [5], 专业的核心课程也是从具体的工作领域转化而 来的。构建以实用工作领域为依托的理论实践一体化的课 程模式, 这是至关重要的。

“三人行，必有我师焉”，法国的小组制诠释了这句 古话。所以教学方式上的改革也要融入这一做法, 摒弃传 统的教学观念, 形成 “老师讲的少一点, 学生自学多一点; 老师做的少一点, 学生动手多一点” 的教学形式, 并且多 让学生以小组的形式进行学习, 这样能够在学习中避免错
误, 扩展思维, 毕竟一个人的能力是有限的; 而且还能培 养学生的团结协作能力和日常交际能力。

\section{2. 发展国内学校与法国工程师学校合作}

中国在《国家中长期教育改革和发展规划纲要 （2010 2020）年》中提到要 “适应国家经济社会对外开 放的要求, 培养大批具有国际视野、通晓国际规则、能够 参与国际事务和国际竞争的国际化人才”。由于教育部在 高等工程教育领域与国际高水平大学协作方面的大力支 持。大批高校应招改革, 以西北工业大学的 “ $3+2$ ” 模式 为例。

INSA-Lyon 作为一所法国一流的五年制工程师院校, 以培养具有人文素养、创新能力和企业家精神的 “精英” 工程师为宗旨 [3]。它独特的课程设置、质与量俱佳的师 资和优越的实验实践环境都在国际工科院校里享誉盛名, 它每年都能够给全球输送大约 800 余名的高质量工科人 才。 
表2 INSA-Lyon机械设计专业工程师阶段部分培养方案。

\begin{tabular}{|c|c|c|c|c|c|c|}
\hline \multicolumn{7}{|c|}{ 第三年（第5学期） } \\
\hline 课程 & 总学期 & 讲座 & 小组研讨 & 实验 & 项目 & 学分 \\
\hline 数学 & 42 & 21 & 21 & & & 3 \\
\hline 数值分析 & 28 & 14 & 14 & & & 2.5 \\
\hline 理论力学 & 42 & 21 & 21 & & & 3 \\
\hline 固体力学 & 35 & 21 & 14 & & & 2.5 \\
\hline 液体力学 & 42 & 21 & 21 & & & 3 \\
\hline 自动控制--机电 & 42 & 21 & 21 & & & 3 \\
\hline 机械设计 & 49 & 21 & & & 28 & 3.5 \\
\hline 机械设计--实习 & 12 & & & 16 & & 1 \\
\hline 制造 & 21 & & 21 & & & 1.5 \\
\hline 制造-一实习作业 & 16 & & 14 & 16 & & 1 \\
\hline 三维测量 & 16 & & & 16 & & 1 \\
\hline 管理 & 21 & & 21 & & 21 & \\
\hline 外语 & 42 & & 42 & & 28 & 1.5 \\
\hline 总计 & 457 & 140 & 195 & 48 & 49 & 29 \\
\hline \multicolumn{7}{|c|}{ 第四年课程（第8学期） } \\
\hline 可塑性 & 21 & & 21 & & & 1.5 \\
\hline 固体力学--实习 & 12 & & & 12 & & 1 \\
\hline 有限元方法 & 42 & 14 & 28 & & & 3 \\
\hline 热力发动机 & 28 & 14 & 14 & & & 2 \\
\hline 热发动机试验 & 12 & & & 12 & & 1 \\
\hline 材料科学-一实习 & 12 & & & 12 & & 1 \\
\hline 非破坏性试验 & 12 & & & 12 & & 1 \\
\hline 理论学与应用 & 35 & 14 & 21 & & & 2.5 \\
\hline 震动--实习作业 & 24 & & & 24 & & 2 \\
\hline 动力复合系统 & 42 & 21 & 21 & & & 2 \\
\hline 控制工程--实习 & 12 & & & 12 & & 3 \\
\hline 编码项目 & 20 & & & & 10 & 1 \\
\hline 数字控制与CAM & 14 & & & & & 5 \\
\hline 制造技术-一实习 & 12 & & & 12 & & 1 \\
\hline 质量学 & & & & 12 & & 1 \\
\hline 外语 & & & & & & 1 \\
\hline 总计 & 450 & 63 & 105 & 108 & 10 & 27.5 \\
\hline \multicolumn{7}{|c|}{ 第五年课程（第九学期） } \\
\hline 从7月到9月 & & & & & 700 & 30 \\
\hline
\end{tabular}

表2仅仅是INSA-Lyon机械设计专业的工程师阶段的 部分培养计划, 从表 2 就不难看出课程强度大, 涉及机械、 信息、电子、材料、物理等多门学科。学生除了要完成300 学时左右的课程外, 还要参加长达几个月的企业实习和各 种形式的学术活动, 理论课基本都配有一定课时的实践课

“重实践, 重创新” 这一点也能小组研讨和实验教学的课 时中看出。在每门技术课的课时安排上, 上课教学的时长 只占 $20 \%$ 30\%左右, 其余的时长都是在进行学生自主的研 究、实验或是参加项目。[3]。

西北工业大学借鉴法国高校在工程师培养方面的先 进经验, 成功实现了西北工业大学 “卓越工程师” 培养计 划的改革。在机械工程领域对培养模式、课程体系、教学 方法等方面进行试点, 与法国工程师学校INSA-Lyon合作 探索实践了 “ $3+2$ ” (三年西北工业大学 + 两年法国工程 师学校培养) 本科+硕士 (工程师) 的合作培养模式。根据双 方校方、教授以及首批毕业学生的反馈, 这种合作培养具 有明显的优势。

（1）既保留了西北工业大学的优势，同时借鉴法国 高校的教学经验进行培养方案和课程设置的调整修改, 保 证培养方面的优势互补。培养了大批基础扎实、知识面广、 操作能力强悍、勇于创新的高素质工程人才。
（2）该培养模式有利于培养具有国际视野、通晓国 际规则的创新型技术人才。实践证明，在法国两年的学习 不仅使学生在专业学习上与法国学生同步, 而且学生能够 身临其境地感受法国文化, 进入企业实习, 深入法国生活, 了解法国乃至欧洲社会, 有利于学生国际视野的培养, 更 有利于学生通晓国际规则, 这也是全球化背景下高校人才 培养的所需。该模式有利于学生的发展。学生的选拔过程 十分严格, 法方教授委员会专程来校进行笔试和面试; 选 拔标准高, 与在法国选拔学生的标准无二。在第四年和第 五年的教学过程中学生需通过和法国学生完全一致的课 程考试、考察和实践以及实习的评估, 不合格者将被退回, 这种严进严出的模式对学生是很的挑战 [3]。但是, 当学 生经过 5 年的学习后则可同时获得中法双方的本科和工程 师学位, 这使得学生的就业前景良好。

通过上面案例的分析, 学校与法国工程师学校的合作 有着不少的优点, 值得推广和学习。虽然中国国内已有一 些高校的物联网专业开展了中外高校的合作培养, 引进教 学方法和师资。但是这样是不够的, 需要搭建学生赴外学 习和实践的平台。

学校可以与一些法国在物联网方面专业水平高, 对外 合作基础好的工科院校建立联系, 开展师资互通的交换生 学习制度。在西北工业大学的案例中, 学生在进入三年级 后才开始要兼修法语, 根据学生的反馈一年的法语学习, 使他们留学生活的语言障碍仍是一个较大的难题。所以学 校可以在第一年就集中对学生进行外语教学, 所有外语课 程采用法国原版教材, 学习法国的人文文化。在第二年和 第三年, 可以将物联网的核心基课程开始从中文到法文的 转变, 并由法国教师结合中国教师的上课内容为中国学生 量身定制新的课程建设。在制定课程内容时, 学院可以引 进国际优质课程, 在引进课程的同时也引进了国外资深教 授来学院参与授课, 这样才能够在第四年迅速熟悉国外的 教学环境。为了能达到这样的教学效果, 师资队伍的国际 化是不可避免的, 学校可以从这样三方面在完善师资。第 一, 引进和聘请国外高水平的教师和工程专家。这些专家 既可传授学生最完整的知识, 又可指导和培养中国教师逐 步领会法国在物联网专业的教学特点。第二, 学院可以让 本校教师进行二次学习, 让其至少掌握一门外语, 具有国 际化理念和国际视野。加大物联网专业的具有海外留学经 历和海外学位的人才的占比。第三, 学院组织物联网专业 的教师参加国际合作的物联网科研项目, 学院通过各种途 径增加教师到国外高水平大学进修的机会, 培养所有教师 了解和掌握法国教育理念和法国教学方式, 并了解和掌握 物联网学科的最新科研发展动向。

学生在前三年打好基础的前提下, 以国家公派、学校 支持、企业赞助等多种形式的奖学金为保障, 形成了合理、 稳定的出国交流体系, 以留学生的身份去法国工程学院进 行深度学习, 利用第三方高校物联网专业的教学模式, 师 资力量, 实践环境来巩固学生的理论知识; 利用其系统的 校企合作教学锻炼学生的动手能力和创新能力, 让学生切 身参与到外国物联网企业的项目中去, 体会国外的物联网 技术和工作方式, 拓展专业视野, 了解国外物联网行业发 展的现状和趋势。这样的教学形式更加有利于培养出具有 
国际视野、了解国际规则的创新型技术人才。让学生更加 能够适应国际一体化的社会经济体系。

当然, 学生的双向交流是必要的。国际化的学生交流 应是双向的, 是相互平衡的。学校不仅要把自己学生派出 去学习, 还要把海外的优秀学生吸收进来, 进一步促进本 土教育水平的提高。坚持双向的学生交流, 这对学院本身 的发展和学校硬件建设有着很高的要求。尤其在吸引教育 发达的法国学生来学院学习方面, 这会面临一些实际困难。 但是学校就是要努力克服这些困难, 争取每学期招收几名 法国学生来学院和同期的中国学生一起学习交流, 让法国 学生切身体会学校营造的法语学习环境, 新型课程建设等。 学院可以吸收更多优秀的法国等国家学生来校交流, 促进 高等教育国际化的发展, 实现共同进步。

\section{3. 促进校企合作（双导师制）}

从法国工程师教育中, 很容易看出企业实习在其中扮 演者十分重要的角色。其教学内容是学校与企业共同制定 的, 与行业的及时需求是紧密挂钩的。学校的实践课题, 课程设计内容也多是来源于企业的实际问题。在学习期间, 学校一般会组织学生去企业实习两到三次, 并且时间也会 长达几个月之久, 学生会进入到岗位中去, 与有经验的工 程师交流学习, 并在回到学校之后, 针对实习中的问题进 行研究甚至是提出解决办法。这样的校企合作, 使得学生 在毕业前就对相关的工业生产有了了解, 在毕业后也能够 在最短的时间内运用起自己学到的知识, 使自己尽快过渡 到工作中。

以北航中法工程师学院的办学模式为例, 该学院由享 誉世界的高级工程师培养院校——法国中央理工大学集 团与具有 “红色工程师摇篮” 之称的北京航空航天大学 合作创建, 这个学院结合了中国特色的教育和法国通用工 程师教育的培养理念与教学模式, 在管理运营、学生交换、 师资共享和科研合作等方面进行紧密的协同合作。该学院 注重 “工程” 与 “实践” , 为此学院在企业和工业界间展 开了全方位深度合作，与十几家中外世界500强企业签署 了合作伙伴协议, 在人才培养、科学研究等各个方面进行 紧密合作 $[4]$ 。

实习实践是学生和工程师们培养动手能力和创新能 力的重要环节。国际化的实习实践将有助于学生在实际工 作中了解国际通则, 增进国际视野, 为学生的竞争力培养 打下基础。该学院采用渐进三段式的实习实践方式, 分别 为 1 个月的体验实习、 3 个月的见习实习和 6 个月的实岗实 习。学院每年都有一部分优秀学员学在国外进行实习, 其 余学生也大部分在国际企业完成实习工作。表 3 为北航中 法工程师学院开院后第一第二届毕业生见习实习和实岗 实习情况统计表 [4]。

表3 第一第二届学生实习实践情况统计。

\begin{tabular}{|c|c|c|c|c|c|c|}
\hline \multirow{2}{*}{ 类型 } & & \multicolumn{2}{|c|}{ 地域 } & \multicolumn{3}{|l|}{ 实习行业 } \\
\hline & & 国内 & 国外 & 国际企业 & 国内企业 & 实验室 \\
\hline \multirow{2}{*}{ 见习实习 } & 第一届 & $88 \%$ & $12 \%$ & $71 \%$ & $28 \%$ & $1 \%$ \\
\hline & 第二届 & $73 \%$ & $27 \%$ & $51 \%$ & $37 \%$ & $12 \%$ \\
\hline \multirow{2}{*}{ 实岗实习 } & 第一届 & $56 \%$ & $44 \%$ & $70 \%$ & $24 \%$ & $6 \%$ \\
\hline & 第二届 & $65 \%$ & $35 \%$ & $66 \%$ & $22 \%$ & $12 \%$ \\
\hline
\end{tabular}

国际化的校企合作在北航中法工程师学院中体现在 了三个方面。

第一，实习平台的国际化。学院通过企业合作等形式 与很多知名企业达成合作共识, 其中大部分是法国、美国 等国家中顶级的国际知名企业。学院每年还会有一个叫做 “企业开放日” 的活动, 这个更是在学生和国际企业之间 搭建了良好的桥梁。迄今为止, 该学院共组织 4 届的开放 日活动, 规模也是逐渐扩大, 从最开始的 13 家合作企业扩 展到了现在的 50 余家知名企业, 并且还吸引了法国工商会 (CCI) 的积极参与, 这些措施使得学生的实习实践平台 更加的多元化, 是学生的视野更加广阔。

第二, 实习过程的国际化。学生在渐进三段式实习过 程中, 会接受到严格的国际化培训。实习前, 法方指导团 队为学生讲授实习要求与要点、国际商务礼仪、团队协作 等知识。实习中, 会要求同学根据自己的实习实践过程完 成自己的全英文或法文的实习手册, 定期向法方指导团队 汇报实习进展。学生要在工作过程中向在不同国家的企业 人员学习交流, 并对工作中遇到的实际问题提出自己的解 决想法。学生在这个过程中将大大提升自己的外语表达能 力, 世界观与价值观也会重新建立。

第三，实习管理方式的国际化。学院在实习初期就均 要学生与企业签订实习协议。学生要提交法文的实习总结 报告并进行答辩。实习答辩由中法双方专家评审组共同组 织, 学生进行实习成果展示, 并交替用中、英、法文回答 专家提问, 答辩通过实习才算完成。这样严格的管理方法 也使得实习实践的作用发挥到极致。

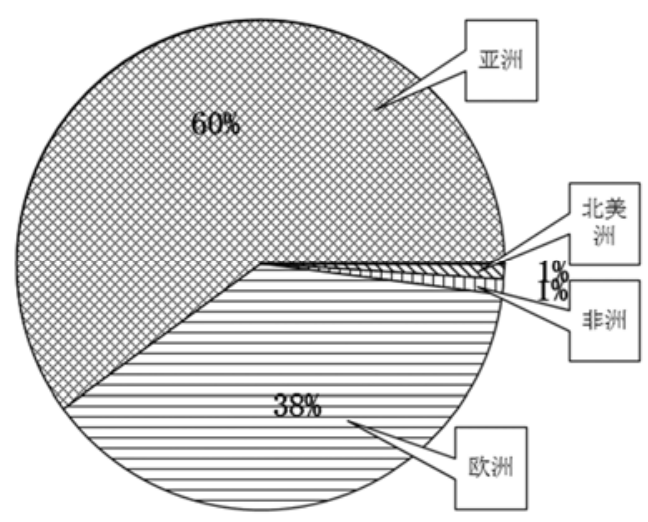

图2 首届毕业生就业地区分布。

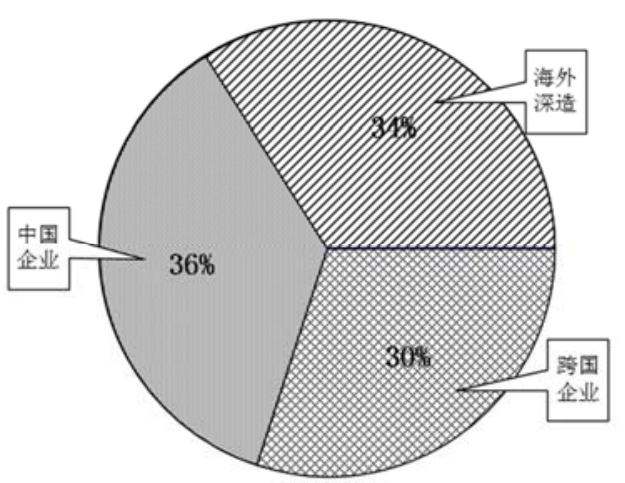

图3 首届毕业生就业行业分布。 
以北航法工程师学院首届学生的就业数据来看, 84 名 毕业生中, 27 名同学赴海外继续深造; 27 名就职于国际知 名的跨国企业; 30 人就职于中国大型国有企业。从工作的 地区来看, 海外深造和就业比例达 40\%（见图2）。从行业 分布来看, $64 \%$ 的学生直接在海外深造或在国际大型企业中 就职, 其余36\%的学生在中国企业中也大多负责与国际相关 的事务 (见图3)。以上数据充分说明了中法工程师学院中 国际化实习实践的重大作用。学院通过企业合作、企业开 放日等措施建立的多方渠道, 既锻炼了学生的动手和创新 能力, 又及时的向学生发布招聘信息并按企业需求进行内 部推荐, 为学生的就职创造了条件。

通过此案例的分析, 纵观我国高校物联网专业现有的 校企合作模式, 大多都是虚有其表, 相关规章制度并不齐 全。有些学校虽然打着校企合作的招牌, 但是只是在四年 的教学过程中去 “观企” , 在企业只停留一两个星期甚至 只有几天, 并没有将学生实际的放到企业中去学习与锻炼; 有些学校的校企合作对象并不达标, 这些企业并没有对高 校学生进行工程技术培训的能力, 这样的校企合作对于学 生的发展也是没有用处的。所以应该加快制定校企合作的 规章制度, 加快校企合作国际化的步伐。这需要国家、学 校和企业三方面的共同配合。学校可以一方面重点考虑与 地方高新物联网企业的合作, 也可与科研院所合作, 提出 由学校和科研院所或企业双面导师培养的物联网教学方 式, 提高学生工程实践能力的创新能力。另一方面在发展 国内高校和法国工程师学院合作的同时, 与法国等发达国 家物联网方面的国际企业取得联系, 建立相互的校企合作 平台。

校企合作的实践教学可分为三次进行。

一年级的时候到企业参观实习。主要了解物联网专业 涉及的产品生产与测试流程, 建立起学生对物联网系统的 整体概念和认识, 了解学校基础课程在整个物联网项目中 的基本应用。

三年级则是到企业实习 $2 \sim 3$ 个月, 要求学生参与到企 业项目的设计、开发、测试、工程实施的流程中去。通过 专业实习使学生将书本中学到的物联网知识化整为零的 融入到项目中去, 感受和了解物联网行业发展的现状和趋 势, 培养初步的实际工作能力和专业能力, 让学生学会怎 样用理论知识来实际解决工程设计、施工、生产中出现的 问题。通过实际操作使学生验证、理解并掌握理论内容, 最后写下自己的实习报告。

最后在四年级的时候, 由于课程的减少, 实习期至少 为半年, 在企业中找一个实习导师, 实现双导师教学, 完 成自己的毕业设计。基于学生的实习环境, 让导师和实习 导师共同拟定一个结合物联网工程现场生产科研中问题 的毕业课题, 在学校和企业的共同指导下, 进行有针对性 的研究和实践, 完成毕业设计。答辩时也可学校企业共同
参加。这三次的实习, 循序渐进的帮学生完成从学校的企 业的转变, 加强学生的就业竞争率。通过联合培养使学生 从学校学习过渡到企业工作中去。

\section{结论}

“取其精华, 去其糟粕” 是对待法国工程师教育的态 度。学习法国工程师教育模式中 “重实践, 重创新” , 将 扎实的基础加上实践能力, 为中国物联网工程师人才的培 养计划添砖加瓦。

\section{参考文献}

[1] 夏松竹. 物联网工程专业卓越工程师人才培养目标和策略 研究 $[J]$. 计算机教育, 2013（23）:98-101。

[2] 杨晓芳. 法国工程师教育模式及启示 $[\mathrm{J}]$. 高等建筑教 育, 2013, 22 。

[3] 孙瑜. 国际化创新型工程人才培养的探索一一来自西北工 业大学与法国 INSA - Lyon “ $3+2$ ” 工程师联合培养模式 的经验 [J]. 高教探索, 2013 (1)。

[4] 于黎明. 高等工程教育发展趋势分析与国际化办学探索 $[\mathrm{J}]$. 北京航空航天大学, 2012。

[5] 张涛. 高职院校 “物联网工程师” 认证课程的实训设计 $[\mathrm{J}]$. 湖北工业大, 2012。

[6] 琚生根. 基于卓越工程师培养的物联网实践教学体系 $[\mathrm{J}]$. 实验科学与技术, 2015（13）。

［7］孙子文. 教育生态视野下物联网工程专业 “卓越工程师培 养计划” 方案研究与探索 [J]. 江南大学, 2013。

[8］李东. 物联网工程专业卓越工程师培养——以哈尔滨工业 大学软件学院为例 $[J]$. 计算机教育, 2015 (9)。

[9] 熊华军. 法国高等工程教育改革的特点及其启示 $[J]$. 现代 教育科学, 2004 (6) :21-23。

[10] 孔寒冰. 法国工程教育系统与学科专业探析 $[J]$. 浙江大 学, 2007。

[11] 于黎明. 法国工程师学历教育解读——基于工业革命和社 会变革分析 $[J]$. 北京航空航天大学学报 (社会科学 版),2013（26）：106-111。

[12] 李兴业. 法国高等工程教育培养模式及其启示 $[J]$. 高等教 育研究, 武汉大学, 1998。 